\title{
VARIABILIDADE GENÉTICA PARA TEOR DE AÇÚCARES REDUTORES EM BATATAS SILVESTRES QUE OCORREM NO SUL DO BRASIL
}

\author{
GENETIC VARIABILITY FOR REDUCING SUGAR CONTENT IN WILD POTATOES THAT \\ OCURR IN SOUTHERN BRAZIL
}

\author{
Carla Simone de Almeida Chalá ${ }^{1}$ Arione da Silva Pereira ${ }^{2}$ Angela Diniz Campos $^{3}$ \\ Judith Viégas ${ }^{4}$ Adriana Tourinho Salamoni ${ }^{5}$
}

RESUMO

Açúcares redutores e matéria seca são características muito importantes em batata para processamento. Duas espécies de batata silvestre, Solanum commersonii, subespécies commersonii e malmeanum, e S. chacoense, subespécie muelleri, ocorrem no Sul do Brasil. Essas espécies são importantes para programas de melhoramento, pois apresentam variabilidade para diversas características importantes, tais como, tolerância à seca e geada, resistências a doenças e insetos e teor de matéria seca. Os objetivos deste trabalho foram verificar a variabilidade genética e estimar a herdabilidade para teor de açúcares redutores em clones de batata silvestre, que ocorrem no Sul do Brasil. Cinqüenta clones de batata silvestre, tomados ao acaso, da coleção mantida na EMBRAPA - Clima Temperado foram cultivados, sob telado, no outono e na primavera de 1996. No outono, 30 e, na primavera, 40 clones produziram tubérculos para análise de açúcares redutores. Os teores de açúcares redutores dos tubérculos foram determinados pelo método de Lane Enyon e identificados pelo método de Somogyi, modificado por NELSON (1944). Os resultados indicaram que as espécies estudadas apresentam variabilidade para teor de açúcares redutores, com alta herdabilidade, principalmente no outono.

Palavras-chave: Solanum commersonii, S. chacoense, herdabilidade.

\section{SUMMARY}

Reducing sugar and dry matter are very important traits in potatoes for processing. Two wild potato species, Solanum commersonii, subspecies commersonii and malmeanum, and $\mathbf{S}$. chacoense, subspecie muelleri, occur in the South of Brazil. These species are important for breeding programs, since they have variability for several important traits, such as drought and frost resistance, disease and insect resistance, and dry matter content.. The objectives of this research were to verify the genetic variability for reducing sugar content in wild potato clones of species that occur in this region and to estimate its heritability. Fifty wild potato clones, aleatorily chosen, of Embrapa Clima Temperado collection were grown in screen house, in autumn and spring season of 1996. In autumn, 30 and, in spring, 40 clones produced tubers for the reducing sugar analysis. Tuber sugar content was determined by using the Lane Enyon method and identified by the Somogyi method, modified by NELSON (1944). The results indicated that these species have genetic variability for reducing sugars, with high heritability, mainly in the fall season.

Key words: Solanum commersonii, S. chacoense, heritability

\section{INTRODUÇÃO}

No Brasil, a batata é considerada a hortaliça mais importante e sua produção é quase toda destinada ao consumo in natura, exceto uma pequena quantidade que é de alguma forma processada (COSTA, 1992). Atualmente, tem-se observado o declínio do consumo de batata fresca devido às dificuldades no armazenamento doméstico, descascamento, fritura ou cozimento (DAVIES \& MACKAY, 1994). Dentre os vários tipos de processamento industrial, destacam-se a batata "chips", batata palha, fritas congeladas, batata desidratada, farinha e amido (SILVA, 1991).

\footnotetext{
${ }^{1}$ Biólogo, MSc., Secretaria Municipal de Saúde e Bem Estar Social, Capão do Leão, RS.

2 Engenheiro Agrônomo, PhD., Bolsista do CNPq. Embrapa Clima Temperado, CP 403, 96001-970 Pelotas, RS. E-mail: arione@cpact.embrapa.br. Autor para correspondência.

${ }^{3}$ Engenheiro Agrônomo, MSc., Embrapa Clima Temperado.

${ }^{4}$ Biólogo, Doutor, Professor Adjunto, Departamento de Zoologia e Genética, Instituto de Biologia, UFPEL.

${ }^{5}$ Engenheiro Agrônomo, MSc., Professor da Escola Agrotécnica Federal de Rio do Sul, SC.
} Recebido para publicação em 06.07.99. Aprovado em 03.05.00 
A industrialização oferece vantagens marcantes em relação ao preparo doméstico. Em primeiro lugar, as indústrias localizam-se no centro das regiões produtoras, favorecendo a obtenção de matéria-prima adequada. Além disso, a indústria pode processar grandes volumes, obtendo lotes relativamente uniformes durante a safra. Isso possibilita a disponibilidade na entressafra, quando a produção e a qualidade da batata são baixas e o preço é alto (PEREIRA, 1987; SILVA, 1991).

Conforme POPP (1993), cerca de 1,5 a $2,0 \%$ da produção nacional de batata é destinada à indústria. Esse percentual denota que a industrialização no Brasil é uma atividade recente em relação a outros países, como os Estados Unidos e Holanda, que utilizam, aproximadamente, $60 \%$ da sua produção para este fim.

As características de especial interesse em batata para o processamento incluem, primeiramente, baixo teor de açúcares redutores (glicose e frutose) e, secundariamente, alto conteúdo de matéria seca (LEMOS, 1996). Os açúcares redutores, em altas concentrações, exercem influência negativa na cor de batata frita (PEREIRA \& CAMPOS, 1999), sendo o escurecimento causado pela reação entre grupos redutores (grupos aldeídos) dos açúcares e grupamentos amino dos aminoácidos, durante a fritura, conhecida como reação de Maillard (BEUKEMA \& VAN DER ZAAG, 1990). O conteúdo de matéria seca (sólidos totais) está diretamente relacionado com o rendimento, absorção de óleo durante a fritura e textura do produto industrializado (PEREIRA, 1987).

Para o desenvolvimento de cultivares com baixo teor de açúcares redutores, os melhoristas têm recorrido a espécies silvestres como Solanum phureja ( CRAIG et al., 1994) e S. goniocalyx (THILL \& PELOQUIN, 1994). O germoplasma de espécies silvestres oferece uma fonte ilimitada de variabilidade genética devido ao fato de sobreviverem nos mais diversos ambientes (CLAUSEN, 1997).

No Sul do Brasil, ocorrem duas espécies de batata silvestre, $\boldsymbol{S}$. commersonii, com as subespécies commersonii e malmeanum, e $\boldsymbol{S}$. chacoense, com a subespécie muelleri. Todas são importantes para programas de melhoramento, pois apresentam características de interesse, tais como tolerância à seca e geada, resistência a doenças (Streptomyces scabies, Erwinia carotovora, Pseudomonas solanacearum ) e insetos, e teores elevados de matéria seca (HAWKES \& HJERTING, 1969; ROCHA 1997).

Os objetivos deste trabalho foram verificar a variabilidade genética e estimar a herdabilidade do teor de açúcares redutores em clones de espécies de batata silvestre que ocorrem na região Sul.

\section{MATERIAL E MÉTODOS}

Cinquienta clones de batata silvestre, tomados ao acaso, da coleção mantida na Embrapa Clima Temperado, foram cultivados no outono e na primavera de 1996. No outono, 30 e, na primavera, 40 clones produziram tubérculos suficientes para a análise de açúcares redutores. Os clones avaliados no outono e/ou na primavera de 1996 estão listados na tabela 1 . No outono, foram estudados 24 clones de S. commersonii (19 da subespécie commersonii e cinco da malmeanum) e seis não identificados. $\mathrm{Na}$ primavera, foram avaliados outros 11 clones de $S$. commersonii (sete da subespécie commersonii e quatro da subespécie malmeanum) e um de $\boldsymbol{S}$. chacoense, subespécie muelleri. Além dos clones silvestres, três clones cultivados de $S$. tuberosum, subespécie tuberosum, foram utilizados como controle: BR-3, Baronesa e C-1582-25-90, que possuem, respectivamente, alto $(1,71 \%)$, médio $(0,57 \%)$ e baixo $(0,21 \%)$ teor de açúcares redutores (PEREIRA \& CAMPOS, 1999).

Os clones silvestres foram plantados sob telado, em sacos plásticos de 8 litros, contendo terra orgânica, com $5 \mathrm{~kg}$ de adubo NPK por $\mathrm{m}^{3}$. O delineamento experimental foi inteiramente casualizado, com duas repetições por tratamento no de outono e três na primavera. Os experimentos foram plantados em 6 de março e 9 de setembro e colhidos em 27 de julho e 6 de dezembro de 1996, respectivamente, no outono e na primavera.

Os tubérculos produzidos no plantio de outono foram armazenados em condições ambiente após a colheita, por duas semanas, à temperatura mínima variando de 3,2 a $11,7^{\circ} \mathrm{C}$ e, à máxima, de 12,2 a $27,4^{\circ} \mathrm{C}$. Os tubérculos produzidos no cultivo de primavera foram armazenados, por doze semanas, à temperatura ambiente, cuja mínima diária variou de 10,8 a $22,0^{\circ} \mathrm{C}$ e, a máxima, de 22,6 a $35,6^{\circ} \mathrm{C}$.

Para a análise da concentração de açúcares redutores, os tubérculos foram lavados e deixados à temperatura ambiente, por 24 horas. Após fatiados, foram mergulhados em solução de bissulfito de sódio, por um minuto, e colocados em estufa a $55-65^{\circ} \mathrm{C}$, por 24 horas. Logo em seguida, as fatias desidratadas foram moídas.

Tabela 1 - Esquema da análise de variância para teor de açúcares redutores.

Causa da Variação Quadrado Médio Esperança do Quadrado Médio

\begin{tabular}{lll}
\hline Genótipos & $\mathrm{QM}_{1}$ & $\sigma^{2} \mathrm{e}+\mathrm{r} \sigma^{2} \mathrm{~g}$ \\
Erro & $\mathrm{QM}_{2}$ & $\sigma^{2} \mathrm{e}$ \\
\hline
\end{tabular}


As concentrações de açúcares redutores foram determinadas pelo método de Lane Enyon, citado na AOAC (1970), e identificadas pelo método de Somogyi, modificado por NELSON (1944).

As análises estatísticas foram realizadas com o programa SAS (Statistical Analysis System). As análises de variância foram computadas, de acordo com a tabela 1, para estimar as variâncias genéticas $\left(\sigma_{\mathrm{g}}^{2}=\mathrm{QM}_{1}-\mathrm{QM}_{2} / \mathrm{r}\right)$, ambientais $\left(\sigma_{\mathrm{e}}^{2}=\mathrm{QM}_{2}\right) \mathrm{e}$ herdabilidades $\left(\mathrm{h}^{2}\right)$.

A herdabilidade foi estimada, no presente trabalho, para determinar a proporção da ação gênica e do ambiente na expressão das características de açúcares redutores, com base na média dos clones, de acordo com a seguinte fórmula (VENCOVSKY \& BARRIGA, 1992):

$$
\hat{\mathrm{h}}_{\mathrm{m}}^{2}=\hat{\sigma}_{\mathrm{g}}^{2} /\left(\hat{\sigma}_{\mathrm{g}}^{2}+\hat{\sigma}_{\mathrm{e}}^{2} / \mathrm{r}\right)
$$

\section{RESULTADOS E DISCUSSÃO}

A concentração média geral de açúcares redutores encontrada nos tubérculos dos clones do cultivo de outono foi o dobro $(0,59 \%)$ da observada na primavera $(0,28 \%)$ (Tabela 2$)$. No outono, as concentrações médias de açúcares redutores variaram de $0,16 \%$, para o clone 110 , a $2,77 \%$, para o clone 104 , sendo que os clones de $\boldsymbol{S}$. commersonii subespécie commersonii exibiram teores médios de $0,59 \%$ e, da subespécie malmeanum, de 0,33\%. Vinte por cento dos clones apresentaram níveis de açúcares redutores iguais ou inferiores ao controle para baixa concentração $(\mathrm{C}-1582-25-90=0,26 \%)$, sendo, a maioria deles, da subespécie malmeanum (clones 08 e $64=0,25 \%$ ) e de espécies não identificadas (clones: $105=0,26 \%, 110=0,16 \%$ e $244=$ $0,20 \%$ ). A maioria dos clones exibiu concentração de açúcares redutores intermediária aos controles C1582-25-90 e Baronesa. Apenas o clone 104 (2,77\%) apresentou teor de açúcares redutores mais elevado do que o controle BR-3 (2,20\%).

Na primavera, $35 \%$ dos clones exibiram teores de açúcares redutores iguais ou inferiores ao do clone C-1582-25-90 (0,21\%), predominando, também, clones de $S$. commersonii malmeanum, os quais exibiram teores médios de 0,22\% (Tabela 2). O clone $244(0,67 \%)$ foi o que apresentou a maior concentração de açúcares redutores, com nível semelhante ao controle médio Baronesa $(0,63 \%)$.

Segundo BEUKEMA \& VAN DER ZAAG (1990), são aceitáveis para processamento concentrações de açúcares redutores não superiores a $0,20 \%$, para batata 'chips' e $0,40 \%$, para batata frita na forma de palito, grânulos e flocos. Assim, apenas $6,7 \%$ (dois) dos clones estudados estariam dentro dos limites aceitáveis de açúcares redutores para a elaboração de 'chips', no cultivo de outono, e $32,5 \%$ (13), no cultivo de primavera. Para batata palito, grânulos e flocos, 46,7\% (14) dos clones teriam teores de açúcares redutores aceitáveis, no cultivo de outono, e 90,0\% (36), na primavera.

Os valores de açúcares redutores obtidos neste trabalho mostram uma grande variação, principalmente, entre os clones no cultivo de outono e na resposta dos clones aos dois períodos de cultivo, concordando com a assertiva de DALE \& MACKAY (1994), quando ressaltam que o conteúdo de açúcares dos tubérculos variam consideravelmente entre cultivares, locais e período de cultivo. Na Região Sul, o cultivo de outono caracteriza-se por fotoperíodos e temperaturas decrescentes, permitindo a exposição dos tubérculos a baixas temperaturas $\left(<10^{\circ} \mathrm{C}\right)$, mesmo ainda antes da colheita, o que propicia a conversão do amido em glicose e provoca um aumento indesejável no conteúdo de açúcares redutores. Esse processo é conhecido por adoçamento de baixa temperatura (AP REES $\boldsymbol{e}$ t $\boldsymbol{a l}$., 1981). No presente estudo, a redução da temperatura ocorrida no final do ciclo, no cultivo de outono, deve ter estimulado o acúmulo de açúcares redutores nos tubérculos. Enquanto que, na primavera, as temperaturas ambientais mais elevadas durante a maturação e armazenamento dos tubérculos não favoreceram ao acúmulo de açúcares redutores.

A análise da variância mostrou diferenças significativas no teor de açúcares redutores entre os clones silvestres (Tabela 3), indicando variação para essa característica. Na literatura, não foi encontrado relato de variação genética significativa para açúcares redutores em $\mathbf{S}$. commersonii.

A estimativa da variância genética para açúcares redutores em tubérculos do cultivo de outono foi relativamente grande, sendo de magnitude suficientemente importante para o melhoramento, mesmo que aumentada pela variância do ambiente (Tabela 3). A variância genética no cultivo de primavera foi de baixa magnitude, indicando o pequeno componente genético na população cultivada nesse período. Inclusive, a variância do erro foi superior à variância genética.

A variação quantitativa no número de clones para teor de açúcares redutores no outono (2 clones $\leq 0,20 \%, 13$ clones $\leq 0,40 \%$ ) foi maior do que na primavera (14 clones $\leq 0,20 \%$, 36 clones $\leq$ $0,40 \%$ ), ratificando claramente a maior variância genética para açúcares redutores no outono. Pode-se afirmar, portanto, que é mais apropriado o melhora- 
Tabela 2 - Média de açúcares redutores em clones de batata silvestre (Solanum spp.) ocorrentes no Sul do Brasil. Pelotas, RS, 1996.

\begin{tabular}{|c|c|c|c|}
\hline \multirow[t]{2}{*}{ Espécie } & \multirow[t]{2}{*}{ Clone } & \multicolumn{2}{|c|}{ Açúcares redutores (\%) } \\
\hline & & Cultivo de outono & Cultivo de primavera \\
\hline \multirow[t]{26}{*}{ S. commersonii commersonii } & 13 & 0,40 & 0,27 \\
\hline & 18 & 0,49 & 0,25 \\
\hline & 26 & - & 0,27 \\
\hline & 31 & 1,65 & 0,35 \\
\hline & 32 & 0,37 & 0,33 \\
\hline & 36 & 0,33 & 0,32 \\
\hline & 54 & 0,22 & 0,25 \\
\hline & 76 & - & 0,35 \\
\hline & 78 & 0,43 & 0,38 \\
\hline & 85 & 0,37 & 0,26 \\
\hline & 103 & - & 0,32 \\
\hline & 116 & 0,60 & 0,34 \\
\hline & 117 & - & 0,27 \\
\hline & 118 & 0,46 & 0,35 \\
\hline & 119 & 0,37 & 0,29 \\
\hline & 120 & 0,70 & 0,19 \\
\hline & 122 & 1,19 & 0,17 \\
\hline & 129 & 0,56 & 0,28 \\
\hline & 131 & 0,49 & 0,48 \\
\hline & 134 & 0,91 & - \\
\hline & 140 & 0,56 & 0,38 \\
\hline & 142 & - & 0,32 \\
\hline & 166 & 0,49 & 0,47 \\
\hline & 168 & - & 0,20 \\
\hline & 195 & - & 0,21 \\
\hline & 202 & 0,62 & 0,39 \\
\hline Média & & 0,59 & 0,31 \\
\hline \multirow{9}{*}{ S. commersonii malmeanum } & 08 & 0,25 & 0,28 \\
\hline & 61 & - & 0,16 \\
\hline & 62 & - & 0,48 \\
\hline & 63 & 0,33 & 0,19 \\
\hline & 64 & 0,25 & 0,18 \\
\hline & 65 & 0,27 & 0,19 \\
\hline & 67 & 0,53 & 0,12 \\
\hline & 69 & - & 0,19 \\
\hline & 109 & - & 0,19 \\
\hline Média & & 0,33 & 0,22 \\
\hline S. chacoense muelleri & 68 & - & 0,17 \\
\hline \multirow[t]{6}{*}{ Espécies não modificadas } & 104 & 2,77 & 0,13 \\
\hline & 105 & 0,26 & 0,17 \\
\hline & 107 & 1,19 & 0,29 \\
\hline & 110 & 0,16 & - \\
\hline & 127 & 0,27 & 0,22 \\
\hline & 244 & 0,20 & 0,67 \\
\hline Média geral & & 0,59 & 0,28 \\
\hline DMS $(5 \%)$ & & 0,70 & 0,20 \\
\hline \multirow[t]{3}{*}{ S. tuberosum tuberosum } & BR-3 & 2,20 & 1,55 \\
\hline & Baronesa & 0,75 & 0,63 \\
\hline & C-1582-25-90 & 0,26 & 0,21 \\
\hline
\end{tabular}

no, as temperaturas baixas $\left(<10^{\circ} \mathrm{C}\right)$ induzem a acumulação de açúcares redutores nos tubérculos, amplificando as diferenças entre os clones, facilitando detectá-las. Os valores obtidos são semelhantes aos encontrados por PEREIRA et al. (1994), ao estudar três populações híbridas de Solanum tuberosum, armazenadas a baixas temperaturas $\left(h^{2}<0,63\right)$.

A constatação de variabilidade genética para açúcares redutores indica a potencialidade das espécies S.commersonii e $S$. chacoense, como fontes importantes ao melhoramento da S. tuberosum para essa característica. A introgressão dessa característica na espécie cultivada, entretanto, demandará manipulação de ploidia devido à diferença de ploidia existente entre estas espécies silvestres $(2 \mathrm{n}=2 \mathrm{x}=$ 24) e $S$. tuberosum $(2 \mathrm{n}=4 \mathrm{x}=$ 48).

\section{CONCLUSÕES}

Com base nos resultados obtidos no presente trabalho, pode-se concluir que as espécies silvestres de Solanum spp. que ocorrem no Sul do Brasil:

a) apresentam variabilidade genética para teor de açúcares redutores, principalmente no outono;

b) possuem herdabilidade moderadamente alta para açúcares redutores no período de outono.

\section{AGRADECIMENTOS}

mento no cultivo de outono, o que é confirmado pelo valor da herdabilidade. Na primavera, não há necessidade de seleção, pois a grande maioria dos clones apresentam as características desejáveis.

A estimativa da herdabilidade para açúcares redutores foi alta no cultivo de outono, e moderada, no período de primavera (Tabela 3). No outo-
Os autores expressam seus agradecimentos ao grupo de apoio do Programa de Melhoramento de Batata da Embrapa Clima Temperado, pela contribuição na condução dos experimentos no telado, e à laboratorista Eliana Mariete da Luz Silveira, pelo apoio técnico na realização das análises no Laboratório de Fisiologia Vegetal.

Ciência Rural, v. 31, n. 1, 2001. 
Tabela 3 - Quadrados médios (QM), variância genética $\left(\sigma^{2} \mathrm{~g}\right)$ e do erro $\left(\sigma^{2} \mathrm{e}\right)$, com respectivos desviospadrões (DP), e coeficiente de herdabilidade $\left(\mathrm{h}_{\mathrm{m}}^{2}\right)$ do teor de açúcares redutores em tubérculos de batata silvestre (Solanum spp.) que ocorrem no Sul do Brasil no outono e na primavera de 1996. Pelotas, RS, 1996.

\begin{tabular}{lccccccc}
\hline Período de cultivo & GL $_{\text {CLONE }}$ & QM $_{\text {CLONE }}$ & GLERRo & GLERRo & $\sigma_{\mathrm{g}}^{2} \pm \mathrm{DP}$ & $\sigma_{\mathrm{e}}^{2} \pm \mathrm{DP}$ & $\mathrm{h}_{\mathrm{m}}^{2}$ \\
\hline Outono & 29 & $0,56^{*}$ & 30 & 0,15 & $0,20 \pm 0,07$ & $0,15 \pm 0,04$ & 0,73 \\
Primavera & 39 & $0,04^{*}$ & 80 & 0,02 & $0,007 \pm 0,002$ & $0,02 \pm 0,002$ & 0,51 \\
\hline
\end{tabular}

* Significativo em nível de $5 \%$ de probabilidade de erro.

\section{REFERÊNCIAS BIBLIOGRÁFICAS}

AOAC. Official methods of analysis. 11 ed. Washington, D.C.: Association of Official Analytical Chemists, 1970. 1015 p.

AP REES, T., DIXON, W.L., POLLOCK, C.J., et al. Low temperature sweetening of higher plants. In: FRIEND, J., RODES, M.J.C. Recent advances in the biochemistry of fruits and vegetables. New York : Academic, 1981. p.4161.

BEUKEMA, H.P., VAN DER ZAAG, D.E. Introduction to potato production. Wageningen : Centre for Agricultural Publishing Documentation (PUDOC), 1990. 208p.

Clausen, A.M. Banco de Papas. Campo y Tecnologia, Balcarce, p.14-15, 1997.

COSTA, D.M. Duas novas cultivares de batata (Solanum tuberosum L.) criadas pela EMBRAPA/CNPF. Horti Sul, Pelotas, v.2, n.3, p.28-31, 1992.

CRAIG, A.L., MORRISON, I., BAIRD, E., et al. Expression of reducing sugar accumulation in interespecific somatic hybrids of potato. Plant Cell Report, v.13, p.401-405, 1994.

DAVIES, H.V., MACKAY, G.R. Exploitation of genetic variation to improve potato quality. Aspects of Applied Biology, v.39, p.45-49, 1994.

DALE, M.F.B., MACKAY, G.R. Inheritance of table and processing quality. In: BRADSAHW, J.E., MACKAY, G.R. Potato genetics. Cambridge : CAB International, 1994. p. 285-315.

HAWKES, J.G., HJERTING, J.P. The potatoes of Ar gentina, Brazil, Paraguay and Uruguay. Oxford : Clarendon, 1969. 525p.
LEMOS, J. Perspectivas para a industrialização da batata. REUNIÃO TÉCNICA ANUAL DE PESQUISA E EXTENSÃO DA CULTURA DE BATATA NO RIO GRANDE DO SUL E SANTA CATARINA, 3, 1996 , Santa Maria, RS. Anais... BISOGNIN, D.A. (Coord.). Santa Maria : CCR/UFSM, 1996. p.26-30.

NELSON, N.A. A photometric adaptation of Somogyimethod for determination of glucos. Journal of Biological Chemistry, Baltimore, v.153, p.375-380, 1944.

PEREIRA, A.S. Composição química, valor nutricional e industrialização. In: REIFSCHNEIDER, F.J.B. (coord.). Produção de batata. Brasília : Linha, 1987. p.12-28.

PEREIRA, A. da S., TAI, G.C.C., YADA, R.Y., et al. Potential for improvement by selection for reducing sugar content after cold storage for three potato populations. Theoretical and Applied Genetics, Viena, v.88, p.678-684, 1994.

PEREIRA, A. da S., CAMPOS, A.D. Teor de açúcares redutores em genótipos de batata (Solanum tuberosum L.). Ciência Rural, Santa Maria, v.29, n.1, p.13-16, 1999.

POPP, P.R. A industrialização de batatas no Brasil. In: BARBOSA, J.T. ENCONTRO NACIONAL DE PRODUÇÃO E ABASTECIMENTO DE BATATA, 7, 1993, Araucária. Anais... Araucária : SOB-SMAG/SMCTIAPAR-EMATER/PR-CEASA/PR-EMBRAPA/SPSB, 1993. p.60-61.

ROCHA, B.E.G. Variabilidade isoenzimática e teor de materia seca dos clones de batata silvestre (Solanum spp.). Pelotas, 1997. 78p. Dissertação (Mestrado em Fitomelhoramento) - Curso de Pós-graduação em Agronomia, UFPEL, 1997.

SILVA, A.C.F. da. Batata: alguns aspectos importantes. Agropecuária Catarinense, Florianópolis, v.4, n.4, p.38-41, 1991.

THILL, C.A., PELOQUIN, S.J. Inheritance of potato chip color at 24-chromosome level. American Potato Journal, Orono, v.71, p.629-646, 1994.

VENCOVSKY, R., BARRIGA, P. Genética biométrica no fitomelhoramento. Ribeirão Preto : Revista Brasileira de Genética, 1992. 486 p.

Ciência Rural, v. 31, n. 1, 2001. 